\title{
Produção de galactooligossacarídeo por Scopulariopis sp.
}

\author{
Production of galactooligosaccharide by Scopulariopis sp.
}

\section{Rosângela dos SANTOS ${ }^{1 *}$, Ana Paula Resende SIMIQUELI ${ }^{1}$, Gláucia Maria PASTORE}

\section{Resumo}

Os galactooligossacarídeos (GOS) são um grupo de oligossacarídeos não digeríveis (NDOs), resistentes às enzimas digestivas do intestino com efeitos similares ao da fibra. Sua ingestão aumenta seletivamente o crescimento das Bifidobacterium e dos Lactobacilus no intestino. O benéfico da ingestão de galactooligossacarídeos ocorre pelo aumento dessas populações de bifidobactérias no cólon, suprimindo a atividade de bactérias putrefativas e reduzindo a formação de produtos tóxicos por fermentação. A cepa de Scopulariopsis sp. apresentou boa produtividade de $\beta$-galactosidase quando crescida em meio de fermentação semissólida. O objetivo deste trabalho foi extrair a enzima $\beta$-galactosidase produzida por uma linhagem de Scopulariopsis sp. e avaliar o efeito da temperatura, tempo de reação, concentração de enzima e lactose para produção de GOS. Foram analisadas as temperaturas 35,45 e $60^{\circ} \mathrm{C}$, os tempos de reação 12,24 e 48 horas, concentrações de enzima 0,5 a 10 U.mL $\mathrm{mL}^{-1}$ e 10, 25 e 40\% (p/v) de solução de lactose (em 0,1 M de tampão acetato de sódio, pH 5.0). As condições ótimas foram de $40 \%$ (p/v), a $45^{\circ} \mathrm{C}, 10$ U.mL ${ }^{-1}$ de enzima e o melhor tempo foi de 12 horas de reação. Nessas condições, a enzima converteu $20 \%$ de lactose em oligossacarídeos (80,8 mg.mL ${ }^{-1}$ de 4 'galactosyl-lactose).

Palavras-chave: alimentos funcionais; prebiótico; $\beta$-galactosidase; Scopulariopis sp.; galactooligossacarídeo.

\begin{abstract}
The galactooligosaccharides (GOS), a group of oligosaccharides, are not digerible carbohydrates (NDOs) and are resistant to hydrolysis by intestine digestive enzymes with similar dietary fiber physiological effect. The benefits of galactooligosaccharides ingestion arise from a population of bifidobacteria in the colon that suppress the activity of putrefactive bacteria and reduce the formation of toxic fermentation products. Scopulariopsis strains showed good productivity of $\beta$-galactosidase when grown in a semi-solid fermentation medium. The aim of this work was to extract the $\beta$-galactosidase from Scopulariopsis sp. and to evaluate the temperature conditions, reaction time, lactose, and enzyme concentration to improve the GOS production. Temperatures of 35,45 , and $60{ }^{\circ} \mathrm{C}$, reaction time at 12,24 and 48 hours, enzyme concentrations from 0.5 to $10 \mathrm{U} \cdot \mathrm{mL}^{-1}$, and 10,25 , and $40 \%(\mathrm{w} / \mathrm{v})$ of lactose solution $(0,1 \mathrm{M}$ of acetate buffer, $\mathrm{pH} 5.0)$ were analyzed. The optimum conditions were $40 \%(\mathrm{w} / \mathrm{v})$, at $45^{\circ} \mathrm{C}, 10 \mathrm{U} \cdot \mathrm{mL}^{-1}$ of enzyme and the optimum time was 12 hours of reaction. Under these conditions, the enzyme converted $20 \%$ of lactose into oligosaccharide $\left(80.8 \mathrm{mg} \cdot \mathrm{mL}^{-1}\right.$ de 4 'galactosyl-lactose).
\end{abstract}

Keywords: functional foods; prebiotic; $\beta$-galactosidase; Scopulariopis sp.; galactooligosaccharide.

\section{Introdução}

Oligossacarídeos e seus derivados são biomoléculas, que têm uma escala de funções importantes nos sistemas biológicos. Eles são bifidogênicos e também ajudam na: i) redução do nível de colesterol sérico; ii) síntese de vitaminas do complexo B; e iii) ajuda na absorção do cálcio da dieta (GAUR et al., 2006).

Os galactooligossacarídeos (GOS) são um grupo de oligossacarídeos compostos por moléculas de galactose ligada à lactose, sendo formados de tri a hexassacarídeos com 2-5 unidades de galactose (SAKO; MATSUMOTO; TANAKA, 1999). Os GOS são carboidratos não digeríveis resistentes às enzimas digestivas e fermentados por bifidobactérias. Os benefícios da ingestão de GOS são o aumento da população de bifidobactérias no cólon e, por efeito antagônico, supressão da atividade de bactérias putrefativas, reduzindo a formação de metabólitos tóxicos (TOMOMATSU, 1994), e produção de ácidos graxos de cadeia curta (ISHIKAWA et al., 2005).
A importância industrial da $\beta$-galactosidase está em sua aplicação na indústria de laticínios. Esta enzima hidrolisa a lactose, carboidrato característico do leite e conhecido popularmente como "açúcar do leite", em seus monossacarídeos glicose e galactose, obtendo assim, alimentos com baixos teores de lactose, melhorando a solubilidade e digestibilidade do leite e derivados lácteos, ideais para consumidores intolerantes à lactose (SANTIAGO et al., 2004).

Recentemente, um dos desenvolvimentos mais significativos na ciência é o de alimentos funcionais, relacionados ao desenvolvimento dos suplementos dietéticos que afetam beneficamente a composição microbiota do intestino. (CHOCKCHAISAWASDEE et al., 2005).

Sabe-se que diversas leveduras e fungos basidiomicetos têm potente atividade de transgalactosilação e eficiente produção de GOS por Sporobolomyces singularis (CRITTENDEN;

Recebido para publicação em 10/5/2008

Aceito para publicação em 4/1/2009 (003473)

${ }^{1}$ Laboratório de Bioaromas, Departamento de Ciência de Alimentos, Faculdade de Engenharia de Alimentos, Universidade Estadual de Campinas - UNICAMP, CP 6121, CEP 13083-862, Campinas - SP, Brasil, E-mail: rosantos@fea.unicamp.br

${ }^{*}$ A quem a correspondência deve ser enviada 
PLAYNE, 1996; ISHIKAWA et al., 2005), Sterigmatomyces eliviae (NAKAKUKI, 2002), Aspergillus oryzae (HSU; YU; CHOU, 2005), Scopulariopsis sp. (ALMEIDA; PASTORE, 2002; PASTORE; PARK 1979).

A enzima $\beta$-galactosidase (EC 3.2.23) é uma enzima comercialmente importante. Ela catalisa a hidrólise de $\beta$-galactopiranosídeos, tais como a lactose, hidrolisando a lactose com a $\beta$-galactosidase, com isso, os problemas associados com a eliminação do soro, cristalização de lactose em certos alimentos congelados e o consumo de leite por indivíduos com intolerância a lactose podem ser aliviados. Além de catalisar a conversão da lactose a glicose e galactose, a $\beta$-galactosidase catalisa também a reação de transgalactosilação; a lactose serve como doador de unidades de galactosil e um aceptor para a fórmula di-, tri- e outros GOS mais elevados (HSU; YU; CHOU, 2005).

Onishi, Kira e Yokozeki (1996) pesquisaram a produção de GOS a partir da levedura Sirobasidium magnum CBS 6803 e verificaram que a produção de GOS aumentou com relação ao tempo. Os autores obtiveram $136 \mathrm{mg} \cdot \mathrm{mL}^{-1} \mathrm{de}$ GOS, compreendido de $124 \mathrm{mg} \cdot \mathrm{mL}^{-1}$ de trissacarídeos e $12 \mathrm{mg} \cdot \mathrm{mL}^{-1}$ de tetrassacarídeos, formados depois de um período de incubação de 42 horas. Verificaram também que os pentassacarídeos e os oligossacarídeos maiores foram formados somente em algumas amostras. Uma quantidade considerável de glicose foi produzida, mas pouca galactose foi formada. Para a retirada da glicose, adicionou-se tolueno tratado com a enzima glicose oxidase e verificou-se que a quantidade de GOS produzido foi de $224 \mathrm{mg} \cdot \mathrm{mL}^{-1}$, incluindo $180 \mathrm{mg} \cdot \mathrm{mL}^{-1} \mathrm{de}$ trissacarídeos e $44 \mathrm{mg} \cdot \mathrm{mL}^{-1}$ de tetrassacarídeo. A produtividade de GOS aumentou consideravelmente, demonstrando que esta combinação foi bastante favorável.

Segundo Carabin e Flamm (1999), a ingestão diária média de oligossacarídeos por pessoa nos Estados Unidos é estimada em aproximadamente 800 a $1000 \mathrm{mg} \cdot \mathrm{dia}^{-1}$. Para melhorar a flora bacteriana, a recomendação usual para o FOS, o GOS, ou inulina são 2000 a $3000 \mathrm{mg} \mathrm{dia}^{-1}$. No caso de pessoas com diabetes e índice elevado de gordura no sangue (colesterol e triglicerídeos), as quantidades variaram de 8 a 20 g.dia $^{-1}$. Geralmente, os oligossacarídeos são bem tolerados, em alguns casos foi relatado aumento de flatulência. Em níveis mais elevados de ingestão, isto é, um excesso de 40 g.dia ${ }^{-1}$, GOS e os outros oligossacarídeos podem induzir a diarreia.

Kajiwara, Gandhi e Ustunol (2002) testaram cinco tipos de bifidobactérias intestinais do ser humano, $B$. longum, B. adolescentis, B. breve, B. bifidum, e B. infantis, cultivadas em meio clostridial reforçado (controle) e clostridial reforçado suplementado com $5 \%(\mathrm{p} / \mathrm{v})$ de mel, ou fructo-oligosacarídeo (FOS), ou galactooligossacarídeo (GOS), e a inulina. As amostras inoculadas foram incubadas anaerobicamente a $37^{\circ} \mathrm{C}$ por 48 horas. Os níveis de produtos de fermentação tais como ácidos lático e acético foram medidos por cromatografia líquida de alta eficiência. O mel ocasionou o crescimento das cinco culturas bem como FOS, GOS e a inulina. O mel, o FOS, o GOS e a inulina foram eficazes $(p<0,05)$ em sustentar o crescimento destas culturas, após 24 horas de incubação, em comparação ao tratamento controle.
Almeida (2003) estudou a produção de GOS por $\beta$-galactosidase de Scopulariopsis sp. Este fungo encontrado no solo foi o maior produtor de $\beta$-galactosidase entre os 1067 microrganismos estudados (PASTORE; PARK, 1979). Os pesquisadores avaliaram a influência da temperatura, efeito do $\mathrm{pH}$, concentração da enzima e síntese de galactooligossacarídeos. Foi usada uma concentração de lactose a $40 \%$ (p/v), em tampão acetato de sódio $0,1 \mathrm{M} \mathrm{pH} 4.5$ a $45^{\circ} \mathrm{C}$, incubada com $6 \mathrm{U}_{\mathrm{mL}} \mathrm{m}^{-1}$ de $\beta$-galactosidase, e a enzima converteu $30 \%$ da lactose em oligossacarídeos (224,92 mg.mL $\mathrm{mL}^{-1}$ de 4 'galactosil-lactose).

As técnicas de metagenômica vêm alcançando grande interesse na pesquisa de alimentos. Os pesquisadores Ishikawa et al. (2005) estudaram a produção de $\beta$-galactosidase de Sporobolomyces singularis para a produção de GOS. Sabendose que a produção de GOS é inibida pela presença de glicose, os pesquisadores isolaram um gene mutante do $S$. singularis resistente à glicose e verificou-se que a atividade da enzima do fungo mutante era 10 vezes mais ativa que a enzima mãe.

Chockchaisawasdee et al. (2005) realizaram um estudo da síntese de GOS a partir de Kluyveromyces lactis, em relação à concentração de lactose e concentração da enzima. Os resultados mostraram que a quantidade de GOS formada dependeu da concentração da lactose, mas não da concentração da enzima. O melhor desempenho da produção de GOS foi obtido na temperatura de $40^{\circ} \mathrm{C}$ e pH 7 .

Gaur et al. (2006) estudaram a síntese de GOS por um método apropriado de imobilização de $\beta$-galactosidase de Aspergillus oryzae. A avaliação comparativa das três principais técnicas de imobilização (adsorção, acoplamento covalente de quitosana e agregação de enzima cross-linked - CLEA) de $\beta$-galactosidase por Aspergillus oryzae foi estudada. Estas técnicas foram comparadas em termos de rendimento na preparação do imobilizado, característica enzimática, estabilidade e eficiência na síntese de oligossacarídeos. Usando $20 \%(\mathrm{p} / \mathrm{v})$ de lactose, a enzima imobilizada em quitosana obteve rendimento máximo de oligossacarídeos (17,3\% de açúcar total) quando comparada com a enzima livre (10\%) em 2 horas a $40^{\circ} \mathrm{C}$. CLEA foi escolhida pela eficiência da hidrólise de lactose que obteve $78 \%$ de monossacarídeos em 12 horas.

Reddy (1999) desenvolveu um estudo que usava como substrato oligossacarídeos e inulina obtidos da chicória, com o objetivo de relacionar a ação destes prebióticos com a atividade inibitória do câncer de cólon em animais. Os resultados deste estudo indicaram que a administração dietética de oligofrutose e de inulina inibiu o crescimento dos tumores em animais. $\mathrm{O}$ grau de inibição foi maior nos animais que se alimentaram de inulina do que os se alimentaram de oligofrutose, devido ao estímulo de Bifidobacterium intestinais como Bifidobacterium $\operatorname{logum}$. A inibição carcinogênica foi associada à diminuição de metabólitos tóxicos. Experimentações clínicas associadas aos efeitos anticâncer precisam ser aprimoradas e cuidadosamente estudadas.

Chim et al. (1999) acompanharam um estudo com 12 adolescentes masculinos saudáveis de 14-16 anos. O objetivo deste estudo foi investigar se $15 \mathrm{~g} \cdot \mathrm{dia}^{-1}$ de oligofrutose estimulavam a absorção de cálcio. Um grupo de adolescentes 
recebeu oligofrutose e outro grupo recebeu sacarose (grupo controle) nas três principais refeições do dia. O tratamento foi controlado analisando-se amostras de sangue e urina. Um aumento na absorção de cálcio foi encontrado após o consumo deste oligossacarídeo (diferença de $10.8 \pm 5.6, \mathrm{p}<0,05$ do início). Esses pesquisadores constataram que $15 \mathrm{~g}^{-\mathrm{dia}^{-1}} \mathrm{de}$ oligofrutose estimularam a absorção de cálcio nos adolescentes masculinos.

A dose recomendada para que não ocorra diarreia com a ingestão de oligossacarídeos é estimada em aproximadamente $0,3 \mathrm{~g} \cdot \mathrm{kg}^{-1}$ corpóreo (dados baseados em estudos com japoneses adultos), embora esse valor seja variado, dependendo de vários fatores como estilo de vida, hábito alimentar, casos de doenças cardíacas, diabetes, colesterol sérico, etc. O objetivo de substituir esses açúcares está associado aos efeitos benéficos e também a algumas funções fisiológicas como:

- Conservar a secreção de insulina no pâncreas;

- Melhorar a microflora intestinal;

- Não ser cariogênico;

- Efeito anticâncer; e

- Estimular a absorção de minerais $\left(\mathrm{Mg}^{++} \mathrm{e} \mathrm{Ca}{ }^{++}\right)$.

A comparação do efeito de vários prebióticos tem estimulado pesquisas que analisam seus benefícios em conjunto. Moro et al. (2002) estudaram oligossacarídeos do leite humano acrescentado em fórmulas infantis para estimular o crescimento de Bifidobacterium e Lactobacillus. O efeito de uma mistura de dois prebióticos, os fruto-oligossacarídeos (FOS) e galactooligossacarídeos (GOS), foi analisado em 90 crianças. Amostras fecais foram coletadas para contagem do número de Bifidobactérias, principalmente as do gênero Bifidobacterium, em Unidades Formadoras de Colônias (UFC) e a influência do $\mathrm{pH}$ foi analisada. Várias doses e tempos foram testados com o objetivo de verificar as condições mais adequadas. A dose de $0,8 \mathrm{~g} \cdot \mathrm{kg}^{-1}$ corpóreo de GOS foi a mais adequada em relação à fórmula placebo (à base de maltodextrina). A mistura de GOS e FOS teve efeito estimulante no crescimento de Bifidobacterium e Lactobacillus no intestino, sendo bastante promissora para o uso de suplementos para fórmulas infantis.

A popularidade e a aplicação do GOS como alimento funcional (fator bifidogênico em fórmulas de produtos infantis) estão aumentando. Outro benefício é que a transformação da lactose em oligossacarídeos resulta em produtos com baixo teor de lactose. Sabe-se bem que mais e mais pessoas no mundo sofrem com problemas gastrointestinais por causa do índice elevado de lactose nos produtos lácteos, chamado intolerância à lactose. A busca para sua solução começou por volta de 1970 e continua nos dias de hoje. Nos últimos 30 anos, muitos produtos ricos em lactose foram investigados: iogurtes, manteiga, queijo caseiro, leite desnatado, leite fermentado, bebida láctea, leite em pó, sobremesas, sorvetes (CURDA et al., 2006).

Recentemente, Pérez-Conesa et al. (2006) estudaram a alimentação de sete grupos de ratos durante um mês: um grupo foi alimentado com uma fórmula infantil contendo Bifidobacterium bifidum e Bifidobacterium longum; três receberam fórmulas infantis contendo 4'galactosil-lactose (GOS) a 1,2, 5,0, e 10,0\%; e os outros três receberam fórmulas infantis contendo ambos os ingredientes. Amostras fecais foram coletadas para contagem de microrganismos aeróbicos totais, anaeróbicos totais e Bifidobacterium, durante três períodos: 8-10, 18-20 e 28-30 dias. Resultados mostraram que o número de bifidobactérias foi relativamente maior em relação ao grupo de anaeróbicos no $1^{\circ}$ período. No $2^{\circ}$ período as bifidobactérias diminuíram significantemente, e no $3^{\circ}$ período a contagem de bifidobactérias aumentou, especialmente no grupo alimentado com a dieta contendo GOS 1,2\%.

Em um segundo estudo, 12 crianças foram alimentadas com a fórmula infantil contendo B.bifidum e B. longum, e outras 12 crianças foram alimentadas com a fórmula infantil controle. Amostras fecais foram coletadas nas idades de 1, 3, 5, 7, 9, e 12 meses para contagem de anaeróbicos totais, Bifidobacterium, Clostridios. Em todas as amostras foi medido o $\mathrm{pH}$. Crianças de 7 a 9 meses, alimentadas com a fórmula infantil contendo bifidobactéria apresentaram contagens significantemente mais elevadas de bifidobactéria ( $\mathrm{p}<0.05)$ e um pH fecal mais baixo, quando comparado ao grupo de crianças alimentadas com a fórmula infantil controle.

Com base nestas descobertas, o desenvolvimento de um método de produção de GOS eficiente e barato é altamente desejável. Assim, esta revisão demonstra que pesquisadores de diversos países têm se preocupado em buscar microrganismos capazes de produzir $\beta$-galactosidase, com alta atividade de transgalactosilação para a produção de GOS. Sendo já reconhecido que dietas com estes oligossacarídeos propiciam um bem estar para o indivíduo, esta linha de pesquisa é bastante promissora e, no momento, está em plena expansão.

O objetivo deste trabalho foi extrair a enzima $\beta$-galactosidase produzida por uma linhagem de Scopulariopsis sp. e avaliar o efeito da temperatura, tempo de reação, concentração de enzima e lactose para produção de GOS.

\section{Material e métodos}

\subsection{Microrganismo utilizado}

Como fonte da enzima $\beta$-galactosidase, foi utilizado o fungo Scopulariopsis sp isolado por Pastore e Park (1979), depositado na American Type Culture Collection (ATCC) sob o número 44206.

\subsection{Produção do inóculo}

A preparação da suspensão de esporos foi realizada incubando-se a linhagem do fungo Scopulariopsis sp. Os microorganismos foram cultivados em tubo com meio PDA inclinado por 7 dias a $30^{\circ} \mathrm{C}$. Após a incubação, foram adicionados a cada um dos tubos de cultivo $10 \mathrm{~mL}$ de água destilada e estéril.

A superfície do meio de cultura foi levemente raspada com alça de platina estéril para liberação dos esporos até obtenção de uma suspensão de concentração celular igual a $10^{8}$ esporos $/ \mathrm{mL}$ (PASTORE, 1982). 


\subsection{Preparo do extrato enzimático}

O fungo foi cultivado em fermentação semissólida em meio contendo farelo de trigo e água na proporção de $1: 1(\mathrm{p} / \mathrm{v})$. A suspensão de esporos $\left(10^{8}\right.$ esporos. $\left.\mathrm{mL}^{-1}\right)$ foi adicionada a frasco Erlenmeyer de $500 \mathrm{~mL}$ contendo $20 \mathrm{~g}$ de substrato, previamente esterilizado. Após incubação a $30^{\circ} \mathrm{C}$ por 7 dias, foram adicionados $100 \mathrm{~mL}$ de água destilada. $\mathrm{O}$ meio foi triturado com bastão de vidro para liberação da enzima. A mistura ficou em repouso por 1 hora em banho de gelo. Após a filtração desse material, foi obtido o extrato enzimático bruto. (PASTORE, 1982).

\subsection{Precipitação com álcool etílico}

Para a obtenção da $\beta$-galactosidase, adicionou-se ao filtrado etanol resfriado a $8{ }^{\circ} \mathrm{C}$ até concentração de $70 \%$. Esse extrato alcoólico permaneceu em repouso a $5{ }^{\circ} \mathrm{C}$ por uma hora. Posteriormente foi centrifugado por 10 minutos a $10.000 \mathrm{rpm}, \mathrm{e}$ o precipitado contendo a enzima bruta foi liofilizado. A enzima bruta foi acondicionada em frascos adequados e congelada.

\subsection{Determinação da atividade enzimática}

A atividade da $\beta$-galactosidase (EC 3.2.1.23 $\beta$-galactosídeo galactohidrolase) foi determinada usando o substrato sintético o-nitrofenil $\beta$-D-galactopiranosídeo (ONPG) como substrato (SANTOS, 2006).

\subsection{Produção de galactooligossacarídeo}

A produção de galactooligossacarídeos foi realizada sob agitação constante utilizando a enzima bruta com concentração de 10 U.mL $\mathrm{mL}^{-1}$ em solução de lactose a $40 \%(\mathrm{p} / \mathrm{v})$, preparada em tampão acetato de sódio 0,1 M, pH 5,0. Essa mistura foi incubada a $45^{\circ} \mathrm{C}$ por 12,24 e 48 horas. A reação foi paralisada em banho fervente por 10 minutos e as amostras foram analisadas qualitativamente por cromatografia em papel e quantitativamente por CLAE.

Visando ter um produto livre de impurezas e compostos coloridos, foram adicionados $2 \mathrm{mg}$ de carvão ativado para cada $100 \mathrm{~mL}$ de solução de GOS. A solução foi mantida num recipiente livre de luz e depois filtrada com papel Whatman $\mathrm{n}^{\circ} 1$, utilizando o sistema a vácuo.

A solução de GOS foi concentrada, até $55^{\circ}$ Brix em Evaporador rotativo (Tecnal TE-210, São Paulo, Brasil), à temperatura de $50^{\circ} \mathrm{C}$. Essa concentração facilita sua manipulação e aplicação industrial, por ter viscosidade adequada e inibir o crescimento bacteriano.

\subsection{Efeito da concentração da lactose na síntese de galactooligossacarídeo}

O efeito da concentração da lactose foi observado utilizando-se concentrações de 10, 25 e 40\% (p/v), a 10 U.mL $\mathrm{mL}^{-1}$ de $\beta$-galactosidase, em tampão acetato de sódio $0,1 \mathrm{M}, \mathrm{pH}$ 5,0. $\mathrm{A}$ análise dos resultados foi avaliada por cromatografia em papel Whatman $\mathrm{n}^{\circ} 1$ segundo a metodologia citada por Lund e Wyatt (1973).

\subsection{Efeito da concentração da enzima na síntese de galactooligossacarídeo}

O efeito da concentração da enzima na conversão da lactose em galactooligossacarídeos foi avaliado utilizando-se concentrações de 0,5 a 10 U.mL ${ }^{-1}$ de $\beta$-galactosidase em solução de lactose a $40 \%$.

\subsection{Efeito da temperatura na síntese de galactooligossacarídeo}

O efeito da temperatura foi observado entre 35,45 e $60{ }^{\circ} \mathrm{C}$, com solução de lactose inicial de $40 \%$ em tampão acetato de sódio 0,1 M, pH 5,0 e $10 \mathrm{U} \cdot \mathrm{mL}^{-1}$ de $\beta$-galactosidase.

\subsection{Efeito do tempo de reação na síntese de galactooligossacarídeo}

O perfil da produção de GOS em relação ao tempo foi realizado utilizando-se solução de lactose com concentração inicial de $40 \%$ em tampão acetato de sódio 0,1 M, pH 5,0 e 10 U.mL ${ }^{-1}$ de $\beta$-galactosidase a $45^{\circ} \mathrm{C}$, durante 12,24 e 48 horas de reação.

A análise dos resultados em relação à concentração da enzima, da temperatura e do tempo de reação foi avaliada por Cromatografia Líquida de Alta Eficiência (CLAE) segundo a metodologia citada por Santos (2006).

\section{Resultados e discussão}

\subsection{Produção de $\beta$-galactosidase}

A linhagem de Scopulariopsis sp. teve bom crescimento no meio semissólido composto de farelo de trigo e água na proporção de 1:1 (p/v) e produziu a enzima $\beta$-galactosidase. Esta atividade foi iniciada após o quinto dia de fermentação, atingindo o seu máximo após o sétimo dia de crescimento. A linhagem fúngica sintetizou a enzima sem a necessidade do indutor lactose, demonstrando ser uma enzima constitutiva. A atividade de $\beta$-galactosidase foi acompanhada durante 15 dias de fermentação, como pode ser observado na Figura 1. A maioria dos microrganismos relatados na literatura necessita de lactose para a produção de $\beta$-galactosidase (NAKAO et al., 1994; HSU; YU; CHOU, 2005; ISHIKAWA et al., 2005).

\subsection{Preparação do extrato semipurificado}

Utilizando-se as técnicas de precipitação por álcool etílico, foram obtidos 8,24 g de extrato da enzima $\beta$-galactosidase, por $6,5 \mathrm{~L}$ de extrato bruto. $\mathrm{O}$ etanol foi adicionado lentamente mantendo-se a temperatura em torno de $4{ }^{\circ} \mathrm{C}$. Essa condição branda de precipitação evita que a enzima desnature, perdendo a atividade.

\subsection{Efeito da concentração da lactose na síntese de GOS}

O cromatograma apresentado na Figura 2 mostra os produtos da reação da enzima $\beta$-galactosidase na formação de GOS. Observa-se que os "spots" superiores foram indicados 
como os açúcares glicose e galactose, pela comparação das distâncias percorridas (Rf) pelos padrões e os "spots" indicados por seta, como compostos de maior peso molecular. Pela intensidade de coloração foi observado que, quanto mais lactose houver no sistema maior será a produção de GOS.

O efeito da concentração inicial de lactose é observado em relação ao tempo da síntese de GOS. A transgalactosilação é uma reação cinética favorecida por elevadas concentrações iniciais de lactose. Chockchaisawasdee et al. (2005) testaram quatro concentrações de lactose, sendo 220, 280, 340 e $400 \mathrm{mg} \cdot \mathrm{mL}^{-1}$, juntamente com 2,9, 5,8 e 8,7 U.mL $\mathrm{mL}^{-1}$ da enzima $\beta$-galactosidase de Kluyveromyces lactis, na produção de GOS. Obtiveram a concentração máxima de GOS com $400 \mathrm{mg} \cdot \mathrm{mL}^{-1}$ de lactose (40\%), e 5,8 U.mL $\mathrm{mL}^{-1}$ da enzima, na temperatura $40{ }^{\circ} \mathrm{C}, \mathrm{pH} \mathrm{7,0}$, em 4 horas.

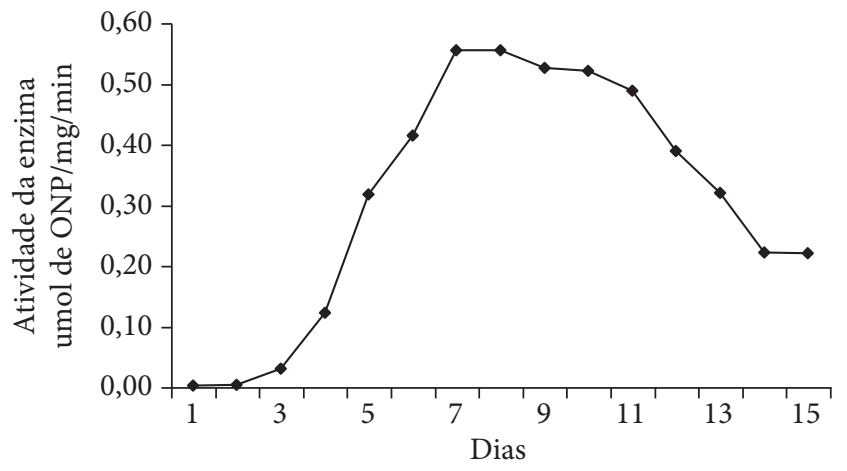

Figura 1. Produção de $\beta$-galactosidase a partir de Scopulariopsis sp., por fermentação semissólido.

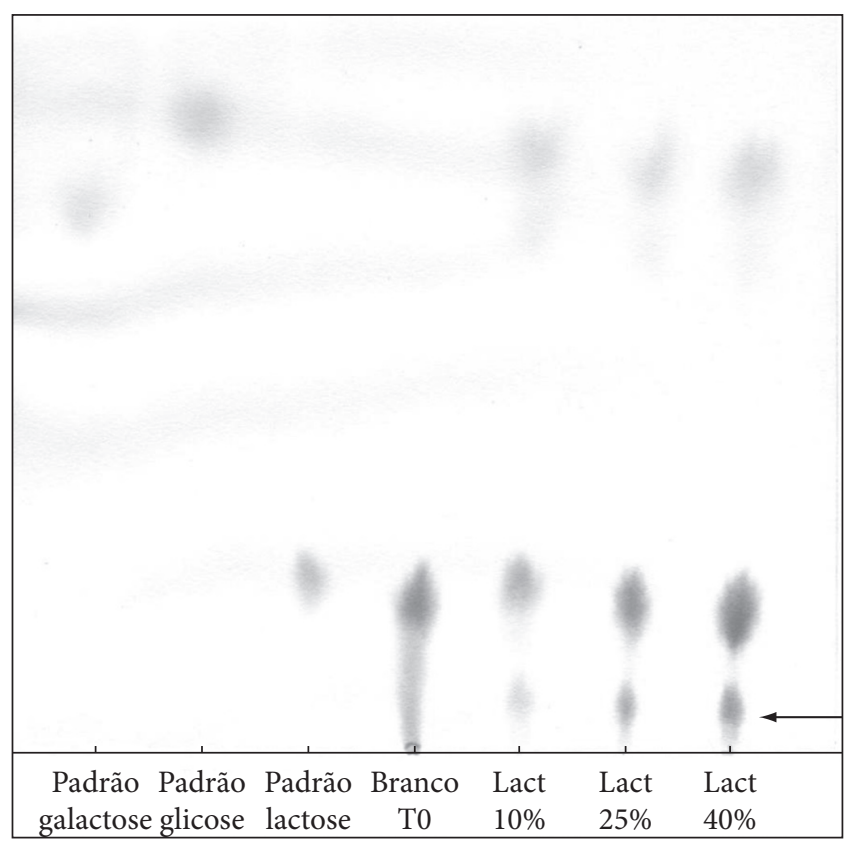

Figura 2. Efeito da concentração de lactose na produção de GOS.

\subsection{Efeito da concentração da enzima na síntese de galactooligossacarídeo}

A reação enzimática na concentração de $0,5 \mathrm{U} \cdot \mathrm{mL}^{-1}$ resultou no menor rendimento até 48 horas de reação e com 1 U. $\mathrm{mL}^{-1}$ de $\beta$-galactosidase houve a necessidade de mais tempo para se alcançar os mesmos níveis obtidos de produto, quando comparado com o emprego de $2 \mathrm{U} \cdot \mathrm{mL}^{-1}$ de enzima. Aumentando-se a concentração de $\beta$-galactosidase para 8 e 10 U.mL $L^{-1}$ houve melhora no rendimento (Figura 3), como já observado na literatura. Chockchaisawasdee et al. (2005) indicaram que o aumento da concentração da enzima não é proporcional ao aumento da síntese de oligossacarídeos, e que a limitação da produção não está relacionada apenas com a concentração da enzima.

\subsection{Efeito da temperatura na síntese de galactooligossacarídeo}

O efeito da temperatura na síntese de galactooligossacarídeos foi observado em 35,45 e $60{ }^{\circ} \mathrm{C}$. Nas análises realizadas com a $\beta$-galactosidase de Scopulariopsis sp., quando a temperatura do sistema de reação era de $35{ }^{\circ} \mathrm{C}$ não houve produção de GOS, em $45^{\circ} \mathrm{C}$ verificou-se que houve produção de GOS em todos os tempos, como mostra a Figura 4, houve diminuição da produçãon de GOS, verificando-se que a temperatura elevada desfavorece a produção de GOS, em tempos de reação prolongado. Ao contrário do resultado obtido por Onishi e Tanaka (1995), verificou-se que a temperatura ótima para reação de transgalactosilação foi de $80{ }^{\circ} \mathrm{C}$ para $\beta$-galactosidase de Sterigmatomyces elviae CBS8119; a produção de GOS pela $\beta$-galactosidase de Scopulariopsis sp. foi mais eficiente com o emprego de temperatura mais branda, $45^{\circ} \mathrm{C}$. Esse efeito foi maximizado em 12 horas de reação.

\subsection{Efeito do tempo de reação na síntese de galactooligossacarídeo}

Para observar a síntese de GOS em relação ao tempo de reação foram fixados os parâmetros considerados mais



Figura 3. Efeito da concentração de $\beta$-galactosidase de 4'galactosillactose, glicose e galactose. 


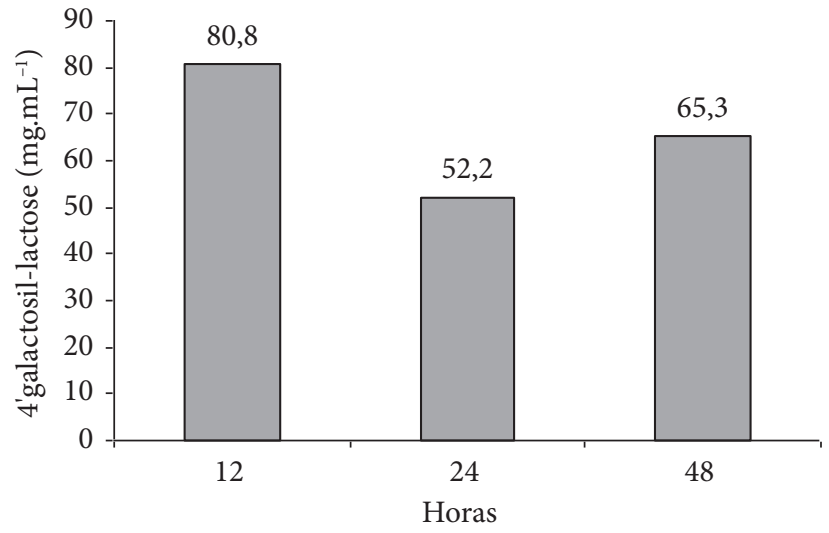

Figura 4. Produção de 4'galactosil-lactose, a $45^{\circ} \mathrm{C}$, a partir de solução de lactose $40 \%$.

satisfatórios para o processo. A concentração de lactose foi fixada em $40 \%$, pois sua hidrólise ocorre predominantemente em baixas concentrações, enquanto que a produção de oligossacarídeos por reação de transgalactosilação ocorre predominantemente em alta concentração do substrato. Vários autores (ALBAYRAK; YANG, 2002; HSU; YU; CHOU, 2005) relatam a importância desta alta concentração na síntese de galactooligossacarídeo.

O trissacarídeo 4'galactosil-lactose foi preferencialmente formado pela $\beta$-galactosidase de Sporobolomyces singularis (ISHIKAWA et al., 2005) e Sterigmatomyces elviae (ONISHI et al., 1996). Outros trissacarídeos como 6'galactosil-lactose foram sintetizados por $\beta$-galactosidase de Aspergillus oryzae (GAUR et al., 2006). Em toda a literatura consultada verificouse que na reação de transgalactosilação catalisada pela $\beta$-galactosidase ocorreu maior formação de trissacarídeos. De acordo com Berger et al. (1995), isto provavelmente ocorra porque os trissacarídeos são os precursores para a síntese dos tetrassacarídeos.

A alta produção de 4'galactosil-lactose [o- $\beta$-D-Gal(1-4)- $\beta$-D-Gal-(1-4)-D-Gli] é de grande interesse porque tem sido considerado um efetivo promotor de crescimento de bifidobactérias (MORO et al., 2002; MWENYA et al., 2004).

A produção de galactooligossacarídeo atingiu seu nível maior de produção a partir de 12 horas de reação, em que se manteve estável (Figura 5), mesmo após 24, e 48 de reação, o que pode ser explicado pelo aumento da quantidade de glicose liberada, considerada um inibidor da reação. Também por apresentarem maior peso molecular que a lactose, os oligossacarídeos podem ser preferencialmente hidrolisados (GOPAL; PRASAD; GILL, 2003).

Após 12 horas de reação, menor quantidade de galactose foi formada em relação à glicose, sugerindo que a enzima $\beta$-galactosidase de Scopulariopsis sp. apresenta maior atividade de transgalactosilação que de hidrólise. Pode-se verificar que, em 12 horas de reação, houve uma conversão de $20 \%$ da lactose em galactooligossacarídeos.

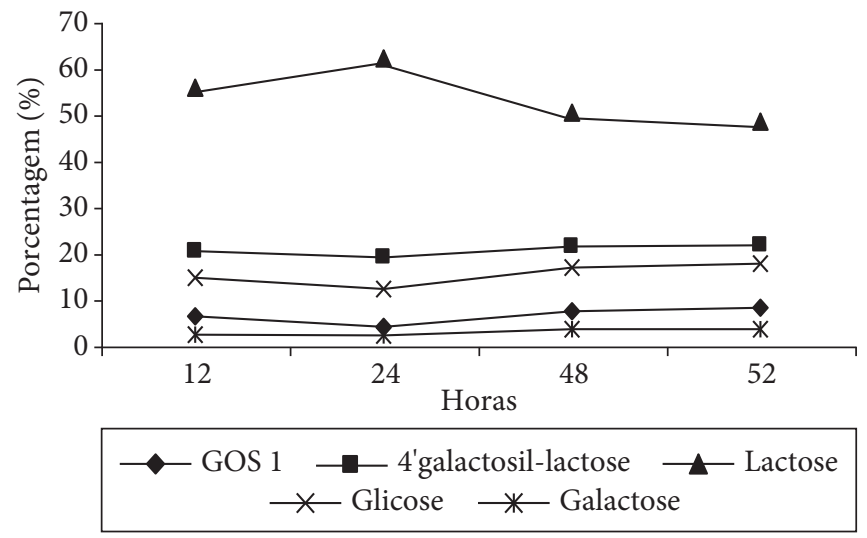

Figura 5. Produção de GOS em relação ao tempo.

Os resultados obtidos neste estudo estão próximos aos encontrados por outros autores, apesar de serem em diferentes condições experimentais. López-Leiva e Guzman (1995), usando $\beta$-galactosidase de Aspergillus oryzae imobilizada, reportaram um rendimento máximo de $14 \%$ de GOS, com 20-40\% de conversão de lactose em GOS. Iwasaki, Misutoshi e Nakao (1996), utilizando a mesma fonte de enzima, obtiveram $32 \%$ de conversão, sendo o sistema de reação composto com $38 \%$ de lactose a $40{ }^{\circ} \mathrm{C}$ e pH 4.5. Onishi e Tanaka (1996) obtiveram $72 \mathrm{mg} \cdot \mathrm{mL}^{-1}$ de GOS após incubação em $20 \%$ de lactose, $\mathrm{pH} \mathrm{5,} 60^{\circ} \mathrm{C}$ por 24 horas. A conversão da lactose foi de $14 \%$ e $\beta$-galactosidase de Aspergillus oryzae levou a 17,9\% de oligossacarídeos, em pH 5 e $35^{\circ} \mathrm{C}$ (RUSTOM; FODA; LOPEZ-LEIVA, 1998). Shin, Park e Yang (1998) produziram $160 \mathrm{mg} \cdot \mathrm{mL}^{-1}$ de GOS utilizando $\beta$-galactosidase de $B$. singularis em $30 \%$ de lactose a $45^{\circ} \mathrm{C}$ e pH 3,7 .

\subsection{Avaliação da produção de galactooligossacarídeos}

A conversão de lactose em GOS foi analisada por CLAE e o perfil cromatográfico obtido está apresentado na Figura 6. Nas amostras analisadas foram identificados os carboidratos galactose, glicose, lactose e 4'galactosil-lactose. A coluna cromatográfica (Supelcogel ${ }^{\mathrm{TM}} \mathrm{Ca}$ ) utilizada na CLAE separa os compostos pelo peso molecular.

Observa-se que o oligossacarídeo 4'galactosil-lactose é eluído antes dos monossacarídeos e da Lactose. Foi observada a formação de outro oligossacarídeo cuja natureza não pôde ser identificada pela inexistência de padrão. Foram realizadas também análises pelo tempo de retenção dos padrões e por cocromatografia.

A enzima obtida a partir de Scopulariopsis sp produziu 80,8, 50,2 e 65,3 mg.mL ${ }^{-1}$ de 4'galactosil-lactose, em relação ao tempo de 12, 24 e 48 horas, respectivamente.

A utilização da $\beta$-galactosidase de Scopulariopsis sp. resultou na síntese de um oligossacarídeo que eluiu em 8,945 minutos, denominado de GOS 1 . O oligossacarídeo denominado de GOS 2 presente nos cromatogramas das reações com ambas as enzimas eluiu em 9,652 minutos, foi identificado como 4'galactosil-lactose, de acordo com padrão autêntico, 


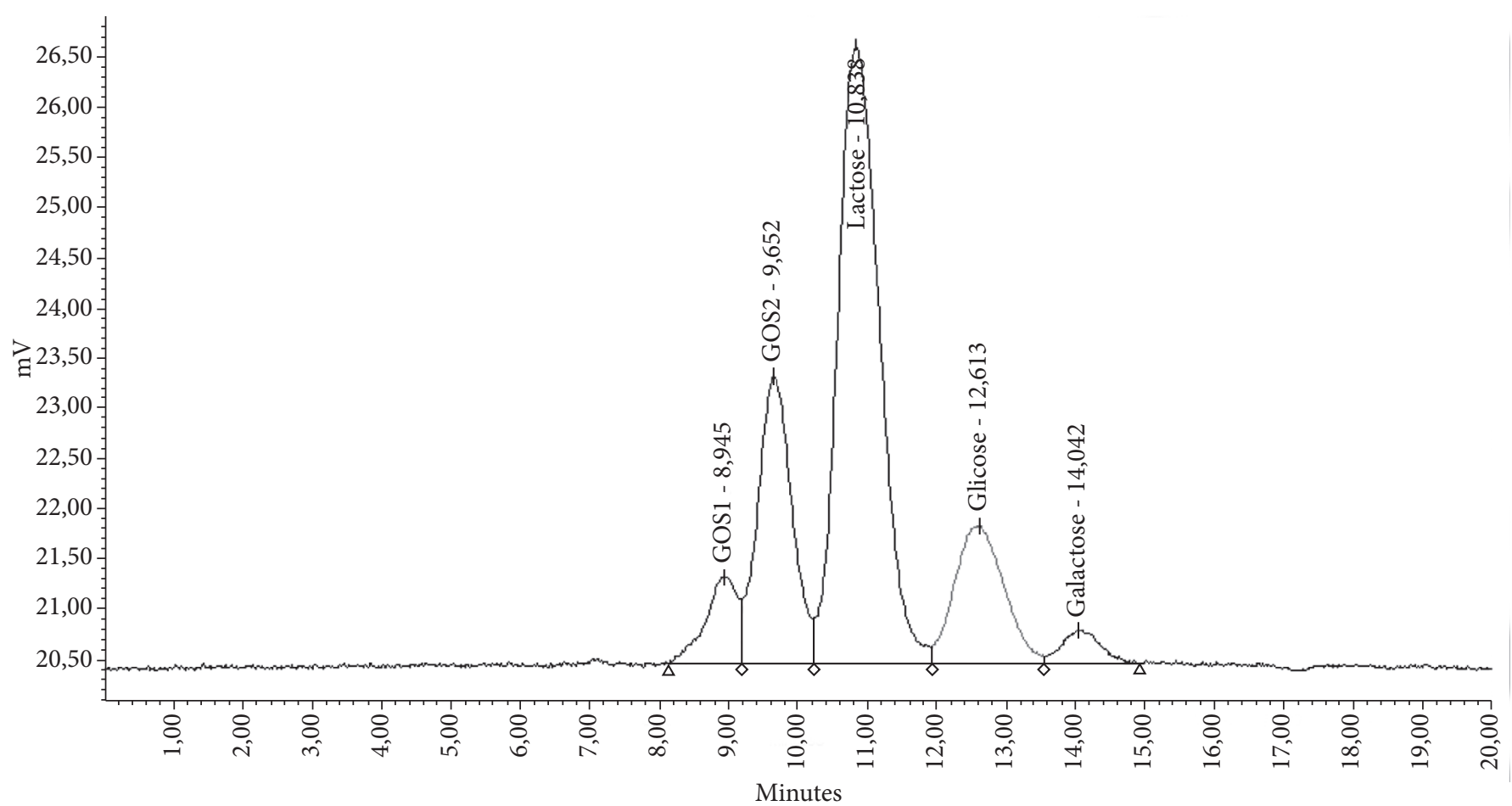

Figura 6. Perfil cromatográfico da mistura de carboidrato por CLAE. Amostra de açúcares obtida após conversão da lactose 40\% (p/v) em GOS, utilizando-se 10 U.mL $\mathrm{mL}^{-1}$ de $\beta$-galactosidase, 12 horas de reação em pH 5.0 à $45^{\circ} \mathrm{C}$.

tendo o mesmo tempo de retenção e também comparado com cocromatografia. A enzima extraída de Scopulariopsis sp. foi eficiente para sintetizá-lo nos variados tempos de reação (12, 24 e 48 horas), analisando a mesma concentração da enzima (10 U.mL $\mathrm{mL}^{-1}$ ).

Foram utilizados $40 \%(\mathrm{p} / \mathrm{v})$ de solução de lactose (em 0,1 M de tampão acetato de sódio), a concentração de enzima para a síntese de GOS foi de $10 \mathrm{U} \cdot \mathrm{mL}^{-1}$, seguindo as condições ótimas de produção de enzima, a temperatura de atividade de galactosiltransferase foi de $45^{\circ} \mathrm{C}, \mathrm{pH}$ 5.0. A enzima obtida a partir de Scopulariopsis sp. converteu 20\% de lactose em oligossacarídeos (80,8 mg. $\mathrm{mL}^{-1}$ de 4'galactosyl-lactose) e o melhor tempo foi de 12 horas de reação.

\section{Conclusões}

O microrganismo Scopulariopsis sp. produziu alta quantidade da enzima $\beta$-galactosidase por fermentação semissólida. A $\beta$-galactosidase de Scopulariopsis sp. apresentou alta atividade de transgalactosilação, sintetizando o trissacarídeo 4'galactosil-lactose. A enzima obtida converteu $20 \%$ de lactose em oligossacarídeos (80,8 mg. $\mathrm{mL}^{-1}$ de 4'galactosyl-lactose).

Os maiores rendimentos de produção de GOS foram obtidos utilizando lactose $40 \%(\mathrm{p} / \mathrm{v})$, a $45{ }^{\circ} \mathrm{C}, \mathrm{pH}$ 5,0 com $10 \mathrm{U} \cdot \mathrm{mL}^{-1}$ de $\beta$-galactosidase, sendo que o aumento da concentração da enzima não é proporcional ao aumento da síntese de GOS, e o melhor tempo foi o de 12 horas de reação.

A busca de novas tecnologias no aumento da produção de galactooligossacarídeo é sugerida em trabalhos futuros, pois foi verificado que a atividade de transgalactosilação da $\beta$-galactosidase de Scopulariopsis sp. é inibida por alguns fatores como o aumento de glicose no sistema.

\section{Referências bibliográficas}

ALBAYRAK, N.; YANG, S. T. Production of galacto-oligosaccharides from lactose by Aspergillus oryzae beta-galactosidase immobilized on cotton cloth. Biotechnology and Bioengineering, v. 77, n. 5, p. 8-19, 2002.

ALMEIDA, M. M. Síntese de Galactooligossacarídeos por $\beta$-galactosidase de Scopulariopsis sp. a partir de lactose. Campinas, 2003. Tese (Doutorado em Ciência de Alimentos) Faculdade de Engenharia de Alimentos, Universidade Estadual de Campinas - UNICAMP.

ALMEIDA, M. M.; PASTORE, G. M. Galactooligossacarídeos Produção e Efeitos benéficos. Boletim da Sociedade Brasileira de Ciência e Tecnologia de Alimentos, v. 35, n. 1/2, p. 12-19, 2002.

BERGER, J. L.; LEE, B. H.; LACROIX, C. Oligosaccharides synthesis by free and immobilized $\beta$-galactosidases from Thermos aquaticus YT-1. Biotechnology Letters, v. 17, n. 10, p. 1077-1080, 1995.

BROUNS, F.; VERMEER, C. Functional food ingredients for reducing the risks of osteoporosis. Trends in Food Science and Technology, v. 11, n. 1, p. 22-33, 2000.

CARABIN, I. G.; FLAMM, W. G. Evaluation of safety of inulin and oligofructose as dietary fiber. Regulatory Toxicology and Pharmacology, v. 30, n. 3, p. 268-282, 1999.

CHOCKCHAISAWASDEE, S. et al. Synthesis of Galacto-oligosaccharide from lactose using $\beta$-galactosidase from kluyveromyces lactis: studies on Membrane-Fitted Bioreactors. Biotechnology and Bioengineering, v. 89, n. 4, p. 434-443, 2005. 
CRITTENDEN, R. G.; PLAYNE, M. J. Production, properties and applications of food-grade oligosaccharides. Trends in Food Science and Technology, v. 7, n. 11, p. 353-361, 1996.

CURDA, L. et al. Dried buttermilk containing galactooligosaccharides: process layout and its verification. Journal of Food Engineering, v. 77, n. 3, p. 468-471, 2006.

GAUR, R. et al. Galacto-oligosaccharide synthesis by immobilized Aspergillus oryzae $\beta$-galactosidase. Food Chemistry, v. 97, n. 3, p. 426-430, 2006.

GOPAL, P. K.; PRASAD, J.; GILL, H. S. Effects of the consumption of Bifidobacterium lactis HN019 (DR10TM) and galactooligosaccharides on the microflora of the gastrointestinal tract in human subjects. Nutrition Research, v. 23, n. 10, p. 1313-1328, 2003.

HSU, C. A.; YU, R. C.; CHOU, C. C. Production of $\beta$-galactosidase by Bifidobacteria as influenced by various culture conditions. International Journal of Food Microbiology, v. 104, n. 2, p. 197-206, 2005.

ISHIKAWA, E. et al. Identification, Cloning, and Characterization of a Sporobolomyces simgularis $\beta$-galactosidase-like Enzyme Involved in Galacto-Oligosaccharide Production. Journal of Bioscience and Bioengineering, v. 99, n. 4, p. 331-339, 2005.

IWASAKI, K.; MISUTOSHI, N.; NAKAO, S. Galacto-oligosaccharide production from lactose by an enzymic batch reaction using by $\beta$-galactosidase. Process Biochemistry, v. 31, n. 1, p. 69-76, 1996.

KAJIWARA, S.; GANDHI, H.; USTUNOL, Z. Effect of honey on the growth of and acid production by human Intestinal Bifidobacterium spp.: An in vitro commercial oligosaccharides and inulin. Journal of Food Protection, v. 65, n. 1, p. 214-218, 2002.

LÓPEZ-LEIVA, M.; GUZMAN, M. Formation of oligosaccharides during enzymic hydrolysis of milk whey permeates. Process Biochemistry, v. 30, n. 8, p. 757-762, 1995.

LUND, B. M.; WYATT, G. M. The nature or reducing compounds formed from sucrose by Erwinia carotovora var. atroseptica. Journal of General and Applied Microbiology, v. 78, n. 2, p. 331-336, 1973.

MORO, G. et al. Dosage-Related bifidogenic effects of galacto- and fructooligosaccharides in formula-Fed term infants. Journal of Pediatric Gastroenterology and Nutrition, v. 34, n. 3, p. 291-295, 2002.

MWENYA, B. et al. Effects of incluing $\beta 1-4$ galacto-oligosaccharides, lactic acid bacteria or yeast culture on methanogenesis as well as energy and nitrogen metabolism in sleep. Animal Feed Science and Technology, v. 115, n. 3-4, p. 313-326, 2004.
NAKAKUKI, T. Present status and future of functional oligosaccharide development in Japan. Pure and Applied Chemistry, v. 74, n. 7, p. 1245-1251, 2002.

NAKAO, M. et al. Purification and characterization of a thermostable $\beta$-galactosidase with high transgalactosylation activity form Saccharopolyspora rectivirgula. Applied Microbiology and Biotechnology, v. 40, n. 5, p. 657-663, 1994.

ONISHI, N.; KIRA, I.; YOKOZEKI, K. Galacto-oligosaccharide production from lactose by Sirobasidium magnum CBS6803. Letters in Applied Microbiology, v. 23, n. 4, p. 253-256, 1996.

ONISHI, N.; TANAKA, T. Purification and properties of a novel thermostable galacto-oligosaccharide producing $\beta$-galactosidase from Sterigmatomyces elviae CBS8119. Applied and Environmental Microbiology, v. 61, n. 11, p. 4026-4030, 1995.

PASTORE, G. M. Produção, purificação, estudos das propriedades e aplicação da $\beta$-galactosidase de Scopulariopsis sp. Campinas, 1982. Tese (Doutorado) - Universidade Estadual de Campinas.

PASTORE, G. M.; PARK, Y. K. Screening of high $\beta$-galactosidase producing fungi and characterizing the hydrolysis properties of a selected strain. Journal Food Science, v. 44, n. 6, p. 1577-1579, 1979.

PÉREZ-CONESA, D. et al. Faecal microbiota changes with the consumption of follow-up formulas containing Bifidobacterium spp. and/or galactooligosaccharides by rats and a folow-up infant formula containing Bifidobacterium spp. by human infants. Journal of food science, v. 71, n. 1, p. M7-M13, 2006.

REDDY, B. S. Possible mechanisms by which pro- and prebiotics influence colon carcinogenesis and tumor growth. The Journal of Nutrition, v. 129, n. 7, p. 1478S-1482S, 1999.

RUSTOM, I. Y. S.; FODA, M. I.; LÓPEZ-LEIVA, M. H. Formation of oligosaccharides from whey UF-permeate by enzymatic hydrolysis analysis of factors. Food Chemistry, v. 62, n. 2, p. 141-147, 1998.

SAKO, T.; MATSUMOTO, K.; TANAKA, R. Recent progress on research and applications of non-digestible galacto-oligosaccharides. International Dairy Journal, v. 9, n. 1, p. 69-80, 1999.

SANTIAGO, P. A. et al. Estudo da produção de $\beta$-galactosidase por fermentação de soro de queijo com kluyvoromyces marxinus. Ciência e Tecnologia de Alimentos, v. 24, n. 4, p. 567-572, 2004.

SANTOS, R. Produção de Galactooligossacarídeo por lactase fúngica. Campinas, 2006. Dissertação (Mestrado) Faculdade de Engenharia de Alimentos, Universidade Estadual de Campinas UNICAMP.

SHIN, H.; PARK, J.; YANG, J. Continuous production of galactooligosaccharides from lactose by Bullera singularis $\beta$-galactosidase immobilized in chitosan beads. Process Biochemistry, v. 33, n. 8, p. 787-792, 1998. 